Referencia para citar este artículo: dos Santos, L. I. C., \& Yamamoto, O. H. (2018). Juventude brasileira em pauta: analisando as conferências e o estatuto da juventude. Revista Latinoamericana de Ciencias Sociales, Niñez y Juventud, 16(2), 657-668. doi:https://doi.org/10.11600/1692715x.16201

\title{
Juventude brasileira em pauta: analisando as conferências e o estatuto da juventude*
}

\author{
LUANA ISABELLE CABRAL DOS SANTOS ** \\ Doutoranda Programa de Pós-Graduação em Psicologia Universidade Federal do Rio Grande do Norte, Brasil. \\ OSWALDO HAJIME YAMAMOTo ${ }^{* * *}$ \\ Professor Universidade Federal do Rio Grande do Norte, Brasil.
}

\section{Artículo recibido en agosto 24 de 2017; artículo aceptado en diciembre 5 de 2017 (Eds.)}

- Resumo (analítico): tendo em vista a situação de vulnerabilidade e visibilidade da juventude, no cenário social e político brasileiro e sua agenda de reivindicações e pautas, objetiva-se discutir aqui o processo de participação política dos jovens. Para tanto, uma das etapas foi a realização de uma análise documental em que se cruzou as propostas aprovadas nas Conferências Nacionais de Juventude com as sessões relacionadas aos direitos dos jovens, presentes no Estatuto da Juventude. Como resultados, observamos que existem demandas específicas (participação política) e outras mais abrangentes, que envolvem toda a sociedade (segurança, educação, mobilidade e saúde), no entanto, existem reivindicações históricas que estão longe de serem transformadas em políticas que efetivem direitos, como as propostas de enfrentamento ao extermínio da juventude negra e uma maior participação política para a juventude.

Palavras-chave: jovens, políticas públicas, participação política, estatuto da juventude (Tesauro da Biblioteca Virtual de Saúde e Psicologia).

\section{Brazilian youth on the agenda: analyzing conferences and the Youth Statute}

- Abstract (analytical): In view of the situation of social vulnerability and limited visibility of youth in the Brazilian social and political contexts and its norms and legislation, the objective of this article is to discuss the process of young people's political participation. To achieve this, a documentary analysis was carried out of the proposals approved in National Youth Conferences as well as the content of the sessions related to the rights of young people contained in the Statute for Youth. As results, the authors identified that there are specific demands from young people (political participation) as well as more encompassing demands that involve all of society (security, education, mobility and health). However, there are historical claims for recognition that are a long way from being transformed into policies to enforce rights, such as proposals to combat the extermination of black youth and greater political participation for young people.

\footnotetext{
* Este artículo de reflexão faz parte da área de conhecimento: Outras Ciências Sociais, subárea: Interdisciplinar. A discussão aqui apresentada é oriunda de uma investigação que discute as possibilidades [concepções e estratégias] de emancipação da juventude no Brasil, a partir da atuação dos movimentos sociais. Possui cofinanciamento da Coordenação de Aperfeiçoamento de Pessoal de Nível Superior (Capes) e foi realizado entre janeiro de 2014 e dezembro de 2016.

** Psicóloga. Mestre em Psicologia. Doutora do Programa de Pós-Graduação em Psicologia da Universidade Federal do Rio Grande do Norte/ Brasil. Integrante do Observatório da População Infantojuvenil em Contextos de Violência (Obijuv) e do Grupo de Pesquisa Marxismo \& Educação (GPM\&E). Orcid: 0000-0001-5182-1691. Índice H5: 1. Correo electrónico: luanaicsantos@gmail.com.

*** Psicólogo. Doutor em Psicologia. Professor titular da Universidade Federal do Rio Grande do Norte/Brasil. Coordenador do Grupo de Pesquisa Marxismo \& Educação (GPM\&E). Orcid: 0000-0001-7870-5666. Índice H5: 23. Correo electrónico: oswaldo.yamamoto@gmail.com.
} 
Key words: Young people, public policies, political participation, statute of youth (Virtual Library Health in Psychology Thesaurus).

\section{Juventud brasileña en el orden del día: analizando las conferencias y el estatuto de la juventud}

- Resumen (analítico): en vista de la situación de vulnerabilidad social y visibilidad de la juventud en el escenario social y político brasileño y su agenda de reivindicaciones, se pretende discutir en este artículo el proceso de participación política de los jóvenes. Para ello, una de las etapas fue la realización de un análisis documental en el que se cruzaron las propuestas aprobadas en las Conferencias Nacionales de Juventud con las sesiones relacionadas con los derechos de los jóvenes presentes en el Estatuto de la Juventud. Como resultados, observamos que existen demandas específicas (participación política) y otras más amplias, que involucran a toda la sociedad (seguridad, educación, movilidady salud), sin embargo, existen reivindicaciones históricas que están lejos de ser transformadas en políticas que hacen efectivos derechos, como las propuestas de enfrentamiento al exterminio de la juventud negra y una mayor participación política para la juventud.

Palabras clave: jóvenes, política pública, participación política, estatuto de la juventud (Thesauro de la Biblioteca Virtual en Salud y Psicología).

-1. Introdução: os marcos da institucionalidade da juventude. -2. Pensar, criar, construir: uma análise das Conferências Nacionais e do Estatuto da Juventude. -3. Reinterpretando a participação política da juventude. -4. Conclusões: Por demandas e direitos: das Conferências ao Estatuto. -Lista de referências.

\section{Introdução: os marcos da institucionalidade da juventude}

O presente artigo busca analisar o momento em que a pauta da juventude começa a impactar a sociedade e produzir uma agenda governamental, que, por sua vez, buscou dar respostas a uma série de demandas e problemáticas que tinha e ainda tem nos jovens seus principais sujeitos. Consideramos que essa reflexão é relevante tendo em vista os importantes ganhos obtidos por esse seguimento, principalmente durante os governos do Partido dos Trabalhadores (PT,) e após anos de militância e luta para o reconhecimento dos/as jovens como sujeitos de direitos.

Ressaltamos que a discussão realizada nesse artigo é oriunda da análise do conteúdo do Estatuto da Juventude - Lei $n^{\circ} 12.852 / 2013$ - e das propostas produzidas e aprovadas nas três Conferências Nacionais de Juventude, ocorridas em 2008, 2011 e 2015. De posse desses documentos, realizamos um cruzamento entre as propostas aprovadas e as seções de direitos presentes no Estatuto, visando entender a relação entre demandas da juventude (incluindo a diversidade desse segmento) e a efetivação das mesmas por meio da criação do Estatuto. Mais especificamente, buscamos analisar, por meio desses instrumentos, o processo de participação política da juventude.

Historicamente, a juventude foi vista a partir de duas lentes: uma que a considera um «problema social», colocando-a no centro dos debates sobre violência e criminalidade e outra em que a juventude é apontada como «protagonista» e «ator estratégico do desenvolvimento» (Bao \& Colognese, 2011). Apesar de ambas as correntes existirem de forma concomitante, objetivamente, o que vimos foi a criação de diversas ações, políticas e programas que atendiam ou correspondiam à primeira visão de juventude, com foco no resgate dos jovens de situações de vulnerabilidade que poderiam, em algum momento, levá-los ao cometimento de delitos, infrações ou crimes (Brasil, 2006).

Em se tratando de assegurar direitos, é necessário dizer que o Brasil seguiu a tendência de outros países da América Latina, a partir da assinatura de pactos e acordos internacionais que visavam mais atenção para os jovens desses países. Sendo assim, como marcos internacionais relacionados à juventude, tivemos: a Declaração sobre a Promoção entre a Juventude dos Ideais da Paz, Respeito 
Mútuo e Compreensão entre os Povos, firmada como compromisso da Organização das Nações Unidas (ONU), em 1965, e a instituição do «Ano Internacional da Juventude», em 1985, firmado também pela ONU (Furiati, 2010). O ano de 1995 foi marcado, mundialmente, pela construção de estratégias de enfrentamento aos desafios postos pela juventude, por meio do Programa Mundial de Ação para a Juventude (PMAJ), aprovado na Assembleia Geral das Nações Unidas; da Declaração de Lisboa sobre a Juventude, lançada após a I Conferência Mundial de Ministros Responsáveis pelos Jovens, em 1998; e, do Plano de Ação de Braga, com origem no Fórum Mundial de Juventude (Silva \& Silva, 2011).

Os marcos internacionais contribuíram para gerar um movimento de pressão, capaz de fazer eco ao que já estava sendo clamado na sociedade e fazer com que houvesse um «reconhecimento da necessidade de políticas públicas de caráter geracional para a juventude, tendo como diretriz a concepção de jovens como sujeitos de direitos» (Silva \& Silva, 2011, p. 666). Dessa forma, a juventude só emerge como um particular «sujeito de direitos» — que demanda «políticas públicas»no início dos anos 1990, momento em que a exclusão desse grupo se torna parte constitutiva da «questão social» ${ }^{1}$ nacional e internacional (Novaes, 2012).

A primeira onda de políticas públicas, voltadas especificamente para a juventude, começa na década de 1990, sob o governo de Fernando Henrique Cardoso (FHC). Nesse período, no Brasil, foram criadas secretarias e coordenadorias municipais e algumas estaduais, muitas vezes, vinculadas a secretarias de esporte e lazer ou assistência social. No entanto, só é possível falar que foi instituído um espaço institucional e uma agenda da juventude a partir dos governos do Partido dos Trabalhadores (PT), inicial e principalmente, com o governo de Luís Inácio Lula da Silva, em 2003.

A partir dos anos 2000 intensificaram-se as discussões, estudos, diagnósticos, assessorias e pesquisas realizadas por diversos órgãos, como a Organização das Nações Unidas para a Educação, a Ciência e Cultura (Unesco), Instituto de Pesquisa Econômica Aplicada (Ipea) y Fórum Brasileiro de Segurança Pública (FBSP) (2017), Instituto Cidadania, Universidades, etc. Com a compilação desse material é que são pensadas ações mais efetivas e articuladas, como a elaboração do Plano Nacional de Juventude - Projeto de Lei (PL n 4.530/2004)—, pela Comissão Especial da Juventude, precedida de ações como audiências públicas e seminários nacionais sobre temas relacionados aos jovens e as organizações de pertencimento dos mesmos. Atualmente, a Lei ainda aguarda ser votada na Câmara dos Deputados, seguindo para as demais instâncias posteriormente.

Em seguida, tivemos a elaboração do Estatuto da Juventude (EJ) — O Projeto de Lei 27/2004pela Comissão Especial da Juventude, que foi aprovado e implantado na forma da Lei $\mathrm{n}^{\mathbf{0}} 12.852$, de 5 de agosto de 2013. Após o PL n ${ }^{0} 4.530 / 2004$ e PL n 27/2004, tivemos a criação da Lei ${ }^{\circ} 11.129$ (Brasil, 2005), que cria a Secretaria Nacional de Juventude (SNJ), o Conselho Nacional de Juventude (Conjuve) e o Programa Nacional de Inclusão de Jovens (ProJovem) — com o objetivo de ofertar uma qualificação profissional em caráter de urgência para os jovens em situação de vulnerabilidade. Os artigos desta Lei devem está em conformidade com a Lei n ${ }^{8} .069$, de 13 de julho (Brasil, 1990), que se refere ao ECA. É inegável o avanço que a criação da Secretaria e do Conjuve traz no âmbito da garantia de direitos para a juventude, ainda que também seja preciso reconhecer que somente essas ações por mais importantes que sejam não garantem o reconhecimento dos jovens como grupo social e político diverso, que possui interesses e necessidades específicas.

Mesmo o governo buscando construir um desenho institucional mínimo, capaz de assegurar efetividade na consolidação de políticas e formas democráticas de gestão (Santos, 2013), a juventude ainda enfrenta situações concretas de desemprego, baixa qualificação, violência, etc., que configuram um quadro de vulnerabilidade social e econômica perverso. O desemprego juvenil, de acordo com os dados da International Labour Office (ILO, 2017), deve atingir a marca de 30\%, ao final desse ano,

1 A «questão social» surge como consequência do antagonismo entre trabalhadores e capitalistas, durante o processo de conformação da sociedade burguesa. Para Iamamoto: «a gênese da questão social encontra-se no caráter coletivo da produção e da apropriação privada do trabalho, de seus frutos e das condições necessárias à sua realização» (2013, p. 330). Essa apropriação privada, por parte do capitalista, da riqueza produzida coletivamente pelos trabalhadores gera uma série de problemáticas políticas, econômicas e sociais. 
sendo o dobro da média mundial (13,1\%) —em 2016, essa taxa ficou em 27,3\%. Para além de uma taxa alta de desemprego, a juventude também tem que lidar com o subemprego e a precarização que os atinge em maior grau. Segundo o estudo das tendências globais de emprego para a juventude em 2017, o desafio que se coloca é: não desperdiçar uma geração de jovens mais qualificados do que a geração anterior e, ao mesmo tempo, garantir o trabalho decente para milhares de jovens.

Com relação à violência, segundo os dados do Ipea y FBSP (2017), entre 2005 e 2015, 318 mil jovens foram assassinados no Brasil, sendo 31.264 (o que equivale a 54,1\% dos homicídios) somente em 2015. Enquanto a taxa média de morte por homicídio da população brasileira é de 28,9 por $100 \mathrm{mil} /$ habitantes, a da população jovem é de 60,9 por $100 \mathrm{mil} /$ habitantes. Os homens jovens continuam sendo as principais vítimas — $92 \%$ dos homicídios - e com relação à cor/etnia, o estudo do Ipea mostra que a cada 100 pessoas mortas, 71 são negras, ou seja, os negros possuem 23,5\% mais chances de serem assassinados em relação a outras raças/etnias, pelo simples componente de cor. Nesse sentido, o estudo mostra que se reduziu a taxa de homicídios de não negros $(12,2 \%)$ e aumentou a de negros (18,2\%). Como os dados apontam, a prevalência de homicídios de homens jovens e negros faz com que esse grupo sofra um processo de «extermínio» que, em grande medida, é legitimado pela ação ou omissão do Estado.

É importante ressaltar que o Brasil, repercutindo o que acontece mundialmente, vem passando por um período de crise e instabilidade - acentuadas após o impeachment da presidenta Dilma Rousseff, em 2016 - que provoca consequências diretas na organização social e política, como por exemplo, o desmonte de algumas Secretarias importantes (a SNJ é uma delas) e uma série de impasses com relação a atuação dos Conselhos, especialmente, o Conjuve. De todo modo, é preciso situar que a criação da Secretaria e do Conselho gerou importantes significados para além de atender o que os movimentos sociais juvenis reivindicavam, como por exemplo, a confirmação da juventude como um grupo social que possui direitos em detrimento de uma concepção que associa esse segmento aos problemas sociais ou como mais um problema social (Brasil, 2010).

Diante desse cenário, podemos perceber dois movimentos: um que avança em direção à conquista e efetivação de direitos e outro, de ofensiva liberal, com a intensificação de pautas conservadoras (vide as dezenas de propostas de redução da idade penal). Nesse sentido, vimos que ainda não foi possível uma cobertura dos direitos sociais ampla, capaz de chegar aos jovens do campo, de povos e comunidades tradicionais e nem àqueles que vivem em extrema pobreza nas grandes cidades. $\mathrm{O}$ desafio de assegurar direitos permanece posto e de forma ainda mais intensa, uma vez que mais medidas e projetos de lei, que estão sendo votados atualmente, atingem diretamente a vida da juventude, como a proposta de reforma do ensino médio ${ }^{2}$.

\section{Pensar, criar, construir: uma análise das Conferências Nacionais e do Estatuto da Juventude}

A análise desses dados tem como pressuposto teórico a perspectiva marxista, isto é, optamos por destrinchar o que avaliamos como os principais produtos das Conferências — as propostas eleitase relacioná-las com a reflexão acerca do Estatuto, uma vez que é ele o instrumento que compila as necessidades e demandas dos jovens. Essas conexões são feitas e pensadas sem perder de vista a totalidade histórica e social, ou seja, entendendo as determinações políticas, econômicas, sociais e culturais que estavam e estão presentes.

É preciso considerar que a estrutura institucional da Política Pública de Juventude ainda é bastante recente, uma vez que faz 11 anos da SNJ e do Conjuve (Brasil, 2014), o que significou um inquestionável avanço, mas também indicou a dificuldade em se considerar os jovens como sujeitos de direitos e, nesse aspecto, criar as condições necessárias para efetivar esses direitos nas três instâncias: União, estados e municípios. Nesse sentido, quando ocorreu a primeira conferência em 2008, não se

2 Em 22 de setembro de 2016 foi encaminhada para o Congresso Federal a Medida Provisória (MP) 746/2016, que trata da reestruturação do Ensino Médio brasileiro. 
tinha ainda a dimensão da proposição de políticas públicas tendo em vista a diversidade da situação juvenil.

A primeira Conferência foi pautada no diagnóstico realizado pelo grupo interministerial que elencou nove prioridades para as políticas públicas de juventude. São elas:

Ampliar o acesso e a permanência na escola de qualidade; erradicar o analfabetismo entre os jovens; preparar para o mundo do trabalho; gerar trabalho e renda; promover vida saudável; democratizar o acesso ao esporte, ao lazer, à cultura e à tecnologia da informação; promover os direitos humanos e as políticas afirmativas; estimular a cidadania e a participação social; e melhorar a qualidade de vida dos jovens no meio rural e nas comunidades tradicionais. (Brasil, 2007, p. 20)

Com esse repertório, ocorreu entre os dias 27 e 30 de abril de 2008, a I Conferência Nacional de Juventude com a participação de aproximadamente 2,5 mil pessoas. Ao final, foram aprovadas 70 resoluções e 22 prioridades sobre os direitos da juventude, que envolvem questões referentes à participação dos jovens nos espaços políticos e que representem a juventude, e o acesso à educação, ao trabalho, cultura e espaços de lazer. Uma das pautas abordadas na conferência foi à necessidade de elaboração de políticas públicas para a juventude negra.

As propostas mais votadas mantiveram a diversidade da juventude no que se refere às demandas de grupos jovens específicos (negros/as, mulheres, de povos e comunidades tradicionais e do campo/rural), assim como, propostas mais gerais relativas à segurança, educação, trabalho, política e participação. Sobre as propostas que surgiram na primeira Conferência, a questão da juventude negra já aparece com relevância na Proposta 1, quando é sinalizada a necessidade de incorporar as resoluções do $1^{\mathrm{o}}$ Encontro Nacional de Juventude Negra (Enjune) às propostas da Conferência, na busca de enfrentar as adversidades que atravessam a vida dessa população, até pouco tempo, bastante invisibilizada.

Também no texto das propostas, já é apontada a pauta política e de participação da juventude - que se repete nas outras Conferências - como prioritária, inclusive esse tema aparece duas vezes: na primeira, ligada à questão da criação do sistema nacional, conselhos e fundos de juventude, ou seja, a criação de uma estrutura capaz de formular políticas, executar e monitorar e, na segunda, se refere à garantia de participação da juventude nos parlamentos, com a destinação de uma «cota» de $15 \%$, garantindo o recorte étnico-racial e paridade de gênero.

Além dos temas importantes, como: educação (básica e superior), trabalho, cultura, esporte e lazer, que também estão presentes na II Conferência, vale ressaltar a prioridade relacionada à segurança, na qual é reforçada a postura contrária à redução da maioridade penal, com a solicitação da aplicação efetiva do ECA — a mesma pauta vai surgir na III Conferência, em virtude da votação desse tema no parlamento federal, durante o ano de 2015, que provocou enorme repercussão na sociedade e que impeliu a atuação mais intensiva dos movimentos sociais de juventude e demais movimentos que militam na área dos direitos humanos e diretos infantojuvenis.

A questão dos Povos e Comunidades Tradicionais já aparece aqui como uma demanda prioritária, na tentativa de se preservar a cultura, linguagem e costumes desses grupos e essa pauta também retorna na III Conferência, indicando que essa questão continua sendo uma preocupação para a juventude e que mais medidas são necessárias para enfrentar toda e qualquer prática de exploração e discriminação que envolva a juventude de povos e comunidades tradicionais, além de buscar garantir o sustento, a partir da reforma agrária e da regularização da documentação de assentamentos já existentes, como propõe a III Conferência.

A II Conferência Nacional de Juventude foi realizada entre os dias 9 e 12 de dezembro de 2011, em Brasília, e contou com representantes dos 26 estados do país mais o Distrito Federal, além de delegações representativas internacionais de 14 países da América do Sul, África, América do Norte e Europa. A II Conferência teve como lema: «Conquistar Direitos, Desenvolver o Brasil». O documento final da II Conferência reforça algumas das demandas e solicitações já presentes na I Conferência, com poucos ajustes, como é o caso da participação dos jovens na política partidária, de forma igualitária, 
considerando a paridade de gênero e uma cota para maior participação da juventude nas coligações eleitorais, assim como, a reivindicação de destinação de $5 \%$ de recursos do fundo partidário para ações da militância juvenil partidária. Com essas propostas, fica visível que a juventude já pedia por uma constituinte exclusiva para uma reforma política.

Como produtos, tivemos a construção de cinco eixos prioritários em relação aos direitos que deveriam ser assegurados:

1. Desenvolvimento integral (educação, trabalho, cultura e comunicação); 2. Território (cidade, campo, transporte público, meio ambiente e comunidades e povos tradicionais); 3. Experimentação e qualidade de vida (saúde, esporte, lazer e tempo livre); 4. Diversidade e vida segura (direitos humanos, segurança, questões etnicorraciais, questões LGBT, gênero); e 5. Participação e fortalecimento institucional. (Brasil, 2011, p. 7)

A juventude reunida em Brasília durante essa II Conferência aprovou uma política e planos que fossem capazes de estender a cobertura a seguimentos mais invisibilizados da juventude. Foi construída a proposta para implantação de política transversal para os jovens portadores de deficiência, com o objetivo de garantir educação, atendimento em saúde e na reabilitação, e inserção no mercado de trabalho, com oferta de qualificação; implantação do Plano Nacional de Enfrentamento à Mortalidade da Juventude Negra, que adota como perspectiva de ação a igualdade racial e o enfrentamento ao racismo por meio de projetos sociais e educativos; e, a implantação do Plano Nacional de Saúde Integral da População de lésbicas, gays, bissexuais e travestis (LGBT), visando superar a situação de vulnerabilidade na saúde, especificamente, desse público.

A II Conferência também foi um passo importante no que se refere à consolidação da participação social como método de gestão nas três esferas de poder. No decorrer das Conferências é perceptível o engajamento dos movimentos sociais de juventude, atuando como atores importantes na formulação e fiscalização das políticas implementadas. A Conferência consolidou diretrizes para os anos seguintes e estabeleceu um conjunto de desafios para o Estado, como por exemplo, a aprovação do Estatuto da Juventude - que aconteceu em 2013- do Plano Nacional de Juventude e a construção do Sistema Nacional de Juventude - esses dois últimos ainda estão em tramitação—, mecanismos concretos que asseguram a institucionalização da política pública.

Por fim, a III Conferência Nacional de Juventude teve como tema «as várias formas de mudar o Brasil» e ocorreu entre os dias 16 e 19 de dezembro de 2015, em Brasília, com a participação de dois mil delegados e vários outros participantes, inclusive, delegações internacionais. A Conferência teve uma programação extensa, composta por formações, debates, apresentações artísticas e grupos de trabalho com o intuito de debater e discutir sobre aspectos que dizem respeito, direta ou indiretamente, as dimensões de vida das juventudes. Foram onze os eixos de debate, em referência ao EJ. São eles: participação, educação, trabalho, diversidade e igualdade, saúde, cultura, direito à comunicação, esporte e lazer, meio ambiente, território e mobilidade, Segurança e paz. Os três pontos prioritários já tinham aparecido como propostas escolhidas nas Conferências anteriores. As prioridades aprovadas são as seguintes:

Segurança: Não à redução da maioridade penal, pelo cumprimento efetivo das medidas previstas no Estatuto da Criança e do Adolescente (ECA); Território: Ampliar e acelerar o processo de Reforma Agrária e regularização fundiária, bem como reconhecimento e demarcação de terras pertencentes a povos e comunidades tradicionais, em especial das terras indígenas e quilombolas, acabando com as práticas forçadas de remoção de seus territórios. Assim, viabilizando a regularização da documentação de assentamentos já existentes, permitindo que os jovens tenham condições de permanecer ou regressar as suas terras originais, e serem assim contemplados pelos programas, projetos e ações para a juventude rural; Participação: Garantir a implantação do Sistema Nacional de Juventude composto por órgãos gestores, conselhos e fundos de públicas de juventude, nas três esferas administrativas. $\mathrm{O}$ fundo nacional de juventude deve funcionar com repasses fundo à fundo definido percentualmente entres os três entes federados para direcionar as políticas e ações para a juventude em âmbito nacional, estadual e municipal. (Brasil, 2016, p. 8) 
Vimos que os resultados oriundos das Conferências foram diferentes. Na primeira, saíram 22 prioridades, na segunda foram 5 eixos prioritários (somando 26 propostas) e na terceira, 3 propostas prioritárias contempladas. O que isso significa e no que isso impacta? Num primeiro olhar, parece não haver continuidade de uma Conferência para outra no que se referem às prioridades que são elencadas em cada ano, mesmo alguns temas se repetindo. Certamente, algumas problemáticas e situações se modificam, podendo deixar de, naquele momento, ser uma prioridade ou ganhar outro status. No entanto, se pensarmos que entre 2008 e 2015 (datas da primeira e da última Conferência) se passaram apenas sete anos e não conseguimos avançar em muitos dos temas que foram considerados importantes naquele primeiro momento, é de se estranhar um pouco o que acontece com esses temas na última Conferência. Inclusive, podemos pensar na diminuição que ocorre ao longo dos anos, de 22 temas prioritários (como já dito), passando por 5 eixos (com 26 propostas), até termos, apenas, 3 pautas prioritárias que devem ser alvo de maior investimento nos próximos anos.

É possível perceber que existe um conjunto de temas ou eixos que são «básicos» e se repetem, como a questão da educação, trabalho e participação, e um conjunto que se diversifica, ganhando mais ou menos espaço a depender da conjuntura sociopolítica, como a redução da idade penal, legalização do aborto, etc. A repetição das demandas, pautas ou bandeiras levantadas pelos movimentos e coletivos de juventude significam a permanência de lutas históricas da juventude. Por exemplo, os temas que se referem à participação e segurança são retomados na última Conferência e possuem forte ligação com a conjuntura política do país, em que temos uma investida do conservadorismo tentando barrar direitos e conquistas sociais, um clima de instabilidade econômica e política, que torna ainda mais necessária a participação dos coletivos e movimentos sociais e a necessidade de demonstrar a força política da juventude.

De acordo com Ortiz-Ruiz (2016), são esses espaços formais, ainda, que possibilitam a participação da juventude na formulação de políticas públicas e abertura de canais de comunicação, em certa medida fluidos e legítimos, entre o Estado e a Sociedade Civil. Por isso, por mais críticas que existam a um modelo tradicional de participação que ocorre nesses espaços, eles ainda são ferramentas importantes que podem ser disputados pela juventude.

No que se refere ao Estatuto da Juventude, ele é criado por meio da lei 12.852/2013, com o objetivo de reafirma a faixa etária da juventude entre os 15 e os 29 anos $^{3}$ e dispor sobre: os direitos dos jovens e as diretrizes para formulação e execução de políticas públicas de juventude, além de prever o estabelecimento do Sistema Nacional de Juventude (Sinajuve). Sobre os direitos previstos no Estatuto, são eles: «direito à cidadania, à participação social e política e à representação juvenil; à educação; à profissionalização, ao trabalho e à renda; à diversidade e à igualdade; à saúde; à cultura; à comunicação e à liberdade de expressão; ao desporto e ao lazer; ao território e à mobilidade; à sustentabilidade e ao meio ambiente; à segurança pública e o acesso à justiça» (Brasil, 2013, pp.7-8).

São, portanto, onze direitos básicos, discriminados em seções, sobre os quais o Estado se coloca como responsável em garantir e assegurar para que os jovens tenham um desenvolvimento pleno e digno. Essa garantia do Estado vem, em grande medida, como um reconhecimento da importância da juventude, mas também por termos chegado em um momento histórico-social em que negar esses direitos seria extremamente prejudicial ao próprio desenvolvimento do país, tendo em vista a situação da juventude e as exigências nacionais e internacionais de enfrentar o quadro de vulnerabilidade social. Além disso, a juventude compõe a População Economicamente Ativa (PEA), assim como, o mercado consumidor, ainda que estudos apontem que os jovens são as pessoas em ocupações mais precarizadas e informais. O EJ também apresenta diretrizes (11), que regem os agentes públicos ou privados envolvidos com a formulação e execução de políticas públicas de juventude e princípios (8) que devem permear todos os aspectos: da formulação dos direitos a sua efetivação por meio de políticas e programas.

3 É importante ressaltar que entre os 15 e 18 anos, os adolescentes são assistidos pelo Estatuto da Criança e do Adolescente (Lei 8.069/1990) e, excepcionalmente, o Estatuto da Juventude, quando não houver conflito com o que é previsto no ECA. 
Segundo Cassettari(2013), as leis específicas contribuem para regulamentar uma lei que é genérica, como nos casos do Estatuto da Criança e do Adolescente, Estatuto do Idoso e, mais recentemente, o Estatuto da Juventude. São leis que tratam de forma mais apropriada de um determinado público, tema ou assunto e que estabelece princípios que devem ser seguidos por todos, além de reconhecer a condição de sujeitos de direitos de todo e qualquer jovem brasileiro. Concordamos com a análise acima, uma vez que, de fato, o Estatuto da Juventude é um grande avanço em direção a efetivação de direitos da juventude, no entanto, o Estatuto ainda possui incompletudes e limites. Portanto, é preciso reconhecer que essas conquistas não são suficientes e que mesmo a implantação de políticas públicas não irá dar conta da diversidade de situações e demandas que perpassam a juventude, o que só poderia ser superado com a superação desse modelo de sociedade que, por sua vez, é baseada na manutenção das desigualdades sociais.

\section{Reinterpretando a participação política da juventude}

Boghossian e Minayo (2009) vão refletir sobre o tema da participação no texto em que fazem uma revisão sistemática sobre juventude e participação nos últimos 10 anos, adicionando a reflexão de outros estudiosos, como Sirvent. Sirvent (2004) vai se referir a duas formas de participação que podem ser resumidas em: participação real e participação simbólica. A primeira ocorre quando há influência efetiva sobre todos os processos em questão, levando, consequentemente a alterações nas engrenagens de distribuição do poder e a segunda acontece a partir da realização de ações de pouca ou nenhuma influência, gerando uma falsa sensação de participação e poder.

Consideramos que em muitos casos, a participação de determinados grupos ocorre de forma simbólica, como denomina Sirvent (2004), uma vez que as decisões que são tomadas nas reuniões e assembleias, muitas vezes, não chegam às esferas do poder público para que assim se transformem em ação, ou quando chegam são arquivadas ou secundarizadas. Um exemplo disso é o próprio Estatuto da Juventude, que demorou em torno de nove anos para ser aprovado (e já era uma reivindicação da juventude organizada até mesmo antes de 2004, ano de criação do projeto de Lei —Brasil, 2004-) e que só o foi depois de muita negociação e retirada ou reescrita de alguns trechos.

Sabemos que a perspectiva da participação é um dos grandes desafios postos atualmente, pois embora esse direito esteja garantido na Constituição Federal e nas legislações mais específicas, ainda encontramos espaços que desconsideram a juventude como ator social importante, com pouca legitimidade e ausência de voz, assim como, esferas em que a juventude sofre tentativas de cooptação por instâncias do poder público. Acreditamos que perspectiva de participação está relacionada ao modelo de democracia que é implantado nas nações.

A democracia moderna foi consolidada em consonância com o desenvolvimento do capitalismo, possuindo, portanto, um caráter burguês e liberal (Motta, 2014). A questão da democracia para muitos autores marxistas também se relaciona com o modo de transição para o socialismo — via reformas ou via revolução. No caso do acúmulo por meio de reformas na política, economia, cultura, etc., se sustenta a tese de que «a democracia possui um valor universal, presente em todas as classes, onde prepondera a decisão majoritária e a defesa das minorias» (Bernstein, 1997, p. 113). Nesse caso, o socialismo teria a ver com «o desenvolvimento e a garantia de uma livre personalidade» e não com a socialização dos meios de produção, que é o que defendem marxistas como Luxemburgo (2011).

Então, para que a cidadania, exercida numa perspectiva democrática, possa exercer a função integradora a qual se propõe, de acordo com Habermas (1997), ela tem que ir além da sua condição jurídica, algo semelhante ao que os autores acima mencionaram. Para Benedicto (2016), a cidadania é baseada numa ideia abstrata de cidadão que precisa possuir determinados padrões, são eles: estar inserido no mercado de trabalho; ser uma pessoa que o Estado reconhece os direitos que, por sua vez, são uma expressão do seu pertencimento a coletividade; cumprir com deveres coletivos, que são definidos, formalizados e regulados pelo Estado, como o pagamento de impostos; manter vínculo com a esfera pública. Todas essas características desconsideram a forte desigualdade econômica e social que é algo inerente ao modo de produção capitalista. 
Diante disso, como fazer a democracia ser capaz de funcionar em sociedades que se complexificam e diversificam cada vez mais? Isso nos leva a duas questões: como falar em participação em sociedades em que a democracia ainda caminha a passos lentos para se consolidar e que, ainda assim terá limites, uma vez que são sociedades capitalistas? E em segundo lugar, precisamos considerar que a forma tradicional de participação apresenta possibilidades, mas, acima de tudo, limites e que só com a ruptura desse sistema é que poderíamos pensar em estruturar uma sociedade verdadeiramente democrática, com a participação ativa e direta de todas e todos, como nos faz refletir Luxemburgo (2011).

No outro lado dessa questão, temos a juventude e um conjunto de autores que concordam que esse grupo social diz muito do momento de uma sociedade, na medida em que está envolvido, geralmente, no processo de transformação do status quo, seja questionando seus valores, seja integrando movimentos e coletivos que buscam mudanças. Assim como Silva (2014), acreditamos que a juventude não é uma categoria estática, pelo contrário, as demandas postas pela diversidade dos jovens estão em constante relação com o período histórico e social determinado. Nesse sentido, o contexto de fortalecimento das juventudes como atores sociais e políticos possibilita a emergência de coletivos e movimentos construídos e organizados por jovens que, por sua vez, sinalizam formas diferentes de engajamento e participação política e social.

Lechner (1990) vai dizer que o desencanto atual do fazer político por parte dos jovens se refere ao estilo gerencial-tecnocrático e não exatamente a um desencanto com a política. Algo sintomático é perceber que se a juventude se afastou de uma militância mais institucionalizada e restrita a determinados espaços públicos (como sindicatos ou conselhos); por outro lado, ocorreu um aumento de outros tipos de ações coletivas, isto é, a juventude passou a se organizar e mobilizar em espaços não institucionalizados, com a criação de formas alternativas de participação, muitas vezes, nos seus próprios territórios. Porém, essas investidas são carregadas de estigmas e preconceitos, o que dificulta sua legitimidade e reconhecimento como forma de participação política efetiva e que reforçam a ideia de que os jovens são apáticos e desinteressados. Como Salienta Arias-Cardona y Alvarado (2015), a relação que a juventude tem estabelecido com a política ocorre, justamente, no movimento dialético de crítica ao modelo tradicional ou convencional e transcendência, no sentido de superação desse modelo. Dentro dessa dinâmica, é possível perceber o desenvolvimento de uma autoconsciência como sujeitos coletivos (Kriger, 2014) que fazem parte de uma sociedade adultocêntrica, que precisa rever suas estruturas.

As jornadas de junho de 2013 exemplificam a forma não convencional do fazer político. Milhares de jovens saíram às ruas por todo o país reivindicando direitos, inicialmente contra $\mathrm{o}$ aumento das tarifas do transporte público, e posteriormente, foram muitas as bandeiras de luta que demonstravam a insatisfação generalizada com a ordem estabelecida. A juventude organizada ou independente demonstrou concretamente novas ferramentas e estratégias de atuação, por meio do uso de novas tecnologias, performances, participação horizontal, realização de assembleias (Berroeta \& Sandoval, 2014), escrachos, entre outros elementos que não só visavam ocupar o espaço público, mas também enviar uma mensagem de que a juventude resiste de forma criativa e coletiva.

As ruas têm sido os espaços públicos por excelência para a ação da juventude, não só no Brasil, mas em vários países, a apropriação do espaço público é um diferencial e ao mesmo tempo algo que garante a identidade da ação dos movimentos de juventude. Em 2011, ocorreram várias marchas/ passeatas no Chile, por exemplo, e ao ocuparem e se apropriarem das ruas (física e simbolicamente), os jovens instalaram um sentimento de mal-estar que denunciava a mercantilização de todas as esferas da vida (Barroeta \& Sandoval, 2014).

Como afirma Castro (2008), temos novas possibilidades de construir uma agenda de luta por transformação social, colocando em evidência rupturas e «implodindo fronteiras e identidades, deslocando a noção do político para as margens do que é convencionalmente concebido como tal» (p. 254), até porque a conquista em participar de espaços políticos, por mais importante que seja, não garante a inserção da juventude como sujeitos políticos e sociais. Como salienta Silva (2014), é preciso estudar essas novas ferramentas e práticas, justamente, pelo seu potencial coletivo, 
transformador e produtor de dissensos, que alarga a noção de política e de participação. E, em se tratando de jovens, como declara Arias-Cardona y Alvarado (2015) é preciso que comecemos a falar de sujeitos políticos ativos, antenados com a construção de suas biografias individuais e suas histórias coletivas e que «reconocen la diferencia y transforman conscientemente las condiciones — políticas, sociales, económicas y culturales — relacionadas con el ejercicio ciudadano» (p. 589).

\section{Conclusão: Por demandas e direitos: das Conferências ao Estatuto}

Este artigo se propõe a fazer um pequeno resgate, a partir da análise das propostas eleitas nas três Conferências Nacionais de Juventude nos dá a dimensão do que aquele agrupamento de jovens, de diferentes estados, etnias, classe social e gênero, reunidos naqueles momentos (2008, 2011 e 2015) pensavam ser importante para garantir em primeira instância, as suas vidas; em seguida, o desenvolvimento pleno e digno. Trazemos esses elementos para pensar que, em primeiro lugar é preciso garantir o direito à vida da juventude, o que não está acontecendo uma vez que os índices de homicídios juvenis aumentam a cada ano - como mencionado na introdução. Sem garantir a vida, fica difícil pensar em qualquer outro direito, por isso a proposta de programas de enfrentamento ao genocídio da juventude negra e também a recusa em aceitar a redução da idade penal (de 18 para 16 anos) _ pautas que se repetiram ao longo das três Conferências.

De modo geral, percebemos que não dá para avaliar rapidamente e de forma meramente comparativa as Conferências, uma vez que o campo da política é marcado por disputas e conflitos e os direitos conquistados precisam ser reafirmados a todo instante. É possível perceber que, até o presente momento, as Conferências costumavam ser espaços legítimos de participação política, nos quais, se fazia uma análise da conjuntura de determinada política ou seguimento da sociedade para se pensar os próximos passos, no sentido de fazer avançar o campo dos direitos. No entanto, o último período da história brasileira tem mostrado que a correlação de forças, nesse momento, não está favorável a classe trabalhadora e a juventude.

Por isso, embora concordemos com Correia Junior (2013), quando ele afirma que o Estatuto é um marco jurídico de garantia de direitos, com reais possibilidades de inclusão social para os jovens brasileiros, sabemos, por outro lado, que ainda há no Estatuto uma série de conteúdos e conceitos que existem muito mais na teoria do que na prática, como a ideia de autonomia, emancipação, participação social e política. Por outro lado — porque a história é dinâmica e dialética — em certa medida, o Estatuto demonstra um processo de mobilização ou «politização» ${ }^{4}$ cada vez maior da juventude, ao participar de forma ativa da luta pela conquista de direitos. Nesse sentido, as ruas, periferias, praças e demais espaços públicos são ocupados e reinventados por meio de vários tipos de linguagens, fazendo coro aos gritos por mais direitos e às reivindicações por uma vida e desenvolvimento digno e pleno.

\section{Lista de referências}

Arias-Cardona, A. M., \& Alvarado, S. V. (2015). Jóvenes y política: de la participación formal a la movilización informal. Revista Latinoamericana de Ciencias Sociales, Niñez y Juventud, 13(2), 581-594. doi:10.11600/1692715x.1322241014

Bao, C. E, \& Colognese, S. A. (2011). A geração que nos critica é aquela que nos criou: gerações, juventude, mudança social. Disponível em: http://www.sbsociologia.com.br/portal/index. php?option=com_docman\&task=doc_download\&gid=1904\&Itemid=170.

Benedicto, J. (2016). La ciudadanía juvenil: un enfoque basado en las experiencias vitales de los jóvenes. Revista Latinoamericana de Ciencias Sociales, Niñez y Juventud, 14(2), 925-938. doi:1 0.11600/1692715x.14203210415

4 Segundo Kriger (2014), o processo de politização é psicossocial, isto é, envolve elementos individuais e coletivos, assim como intra e intersubjetivos, na medida em que se articula com múltiplas dimensões que permitem ao sujeito dar significado a vida em sociedade. 
Bernstein, E. (1997). O socialismo evolucionário. Rio de Janeiro: Jorge Zahar, Instituto Teotônio Vilela.

Berroeta, H., \& Sandoval, J. (2014). Protestas, participación y educación pública: discursos sobre lo público en las movilizaciones estudiantiles en Chile. Educar em Revista, 53, 19-38. doi:10.1590/0104-4060.36578

Boghossian, C. O., \& Minayo, M. C. S. (2009). Revisão sistemática sobre juventude e participação nos últimos 10 anos. Saúde e Sociedade, 18(3), 411-423. doi:10.1590/S0104-12902009000300006

Brasil. (1990). Lei $n^{\circ}$ 8.069, de 13 de julho-Dispõe sobre o Estatuto da Criança e do Adolescente $e$ dá outras providências. Disponível em: <http:/www.planalto.gov.br/ccivil_03/leis/ L8069Compilado.htm>

Brasil. (2004). Projeto de Lei sem número. Institui a aprovação do Plano Nacional de Juventude e dá outras providências. Disponível em: <http://www.dhnet.org.br/dados/pp/a_pdfdht/plano_ nac juventude.pdf $>$

Brasil. (2005). Lei $n^{o} 11.129$, de 30 de junho-Institui o Programa Nacional de Inclusão de JovensProJovem; cria o Conselho Nacional da Juventude-CNJ e a Secretaria Nacional de Juventude; altera as Leis nos. 10.683, de 28 de maio de 2003, e 10.429, de 24 de abril de 2002; e dá outras providências. Disponível em: http://www010.dataprev.gov.br/sislex/paginas/42/2005/11129. htm.

Brasil. (2006). Guia de Políticas Públicas de Juventude. Disponível em: <http://www. secretariadegoverno.gov.br/.arquivos/guiajuventude.pdf $>$.

Brasil. (2007). Documento Base da I Conferência Nacional de Juventude: levante sua bandeira. Disponível em:

$<$ http://acaoeducativa.org.br/antigo/images/stories/pdfs/ $1 \mathrm{a} \% 20$ conferencia $\% 20$ nacional $\% 20$ de $\% 20$ juventude $\% 20-\% 20$ documento $\% 20$ base.pdf $>$.

Brasil. (2010). Conselhos de Juventude: fortalecendo diálogos, promovendo direitos. Brasília: Conselho Nacional de Juventude-Conjuve. Disponível em:

$<$ https://issuu.com/secretariageralpr/docs/juv_guiaconselhos $>$.

Brasil. (2011). $2^{a}$ Conferência Nacional de Políticas Públicas de Juventude "Juventude, Desenvolvimento e efetivação de direitos: conquistar direitos e desenvolver o Brasil”. Disponível em:

$<$ http://juventude.gov.br/articles/participatorio/0016/4420/20110617181625texto_base_da_2a_ conferencia_de_juventude____.pdf $>$.

Brasil. (2013). Lei $n^{\circ} 12.852$, de 05 de agosto. Institui o Estatuto da Juventude e dispõe sobre os direitos dos jovens, os princípios e diretrizes das políticas públicas de juventude e o Sistema Nacional de Juventude-Sinajuve. Disponível em: <http:/www.planalto.gov.br/ccivil_03/_ Ato2011-2014/2013/Lei/L12852.htm>.

Brasil. (2014). Balanço da gestão 2011-2014. Brasília: Secretaria Nacional de Juventude/SNJ. Disponível em: <https://issuu.com/participatorio/docs/balanco_gestao_snj_2011-2014>.

Brasil. (2016). Resolução Final da $3^{a}$ Conferência Nacional de Juventude: as varias formas de mudar o Brasil. Disponível em: <http://juventude.gov.br/articles/participatorio/0017/5777/relatoriofinal-3-conferencia.pdf>.

Cassettari, C. (2013). Estatuto da juventude deve ser votado hoje. Disponível em: <http://www. ibdfam.org.br/noticias>

Castro, L. R. (2008). Participação política e juventude: do mal-estar à responsabilização frente ao destino comum. Revista de Sociologia Política, 16(30), 253-268. doi:10.1590/S010444782008000100015

Correia Junior, C. O. F. (2013). O Estatuto da Juventude: um estudo sobre os limites e possibilidades da nova lei para as políticas públicas de juventude. (Trabalho de conclusão de curso). Universidade Federal Fluminense, Rio das Ostras, Brasil. 
Furiati, N. M. A. (2010). Juventude e Estado no Brasil: a lógica constitutiva do Conselho Nacional de Juventude no governo Lula. (Tese de Doutorado). Universidade Federal de Brasília. Brasília, Brasil.

Habermas, J. (1997). Direito e Democracia: entre facticidade e validade. Rio de Janeiro: Tempo Brasileiro.

Iamamoto, M. V. (2013). O Brasil das desigualdades: «questão social», trabalho e relações sociais. Ser Social, 15(33), 326-342. Disponível em: http:/www.cressrn.org.br/files/arquivos/ FaPa1Oy8kQ65voJ4T345.pdf

Instituto de Pesquisa Econômica Aplicada (Ipea), \& Fórum Brasileiro de Segurança Pública (FBSP). (2017). Atlas da Violência 2017. Brasília: Instituto de Pesquisa Econômica Aplicada (Ipea), Fórum Brasileiro de Segurança Pública (FBSP). Recuperado de: http://www.ipea.gov.br/portal/ images/170609_atlas_da_violencia_2017.pdf

International Labour Office (ILO). (2017). Global Employment Trends for Youth 2017: Paths to a better working future. Geneva: Organização Internacional do Trabalho. Recuperado de: http:// www.ilo.org/wcmsp5/groups/public/---dgreports/---dcomm/---publ/documents/publication/ wcms_598669.pdf

Kriger, M. (2014). Politización juvenil en las naciones contemporáneas. El caso argentino. Revista Latinoamericana de Ciencias Sociales, Niñez y Juventud, 12(2), 583-596. doi:10.11600/169271 $5 \times .1225310314$

Lechner, N. (1990). Los pátios interiores de la democracia. Santiago: Fundo de Cultura.

Luxemburgo, R. (2011). Textos escolhidos. São Paulo: Editora Unesp.

Motta, L. E. (2014). A respeito da questão da democracia no marxismo (a polêmica entre Althusser e Poulantzas). Revista Brasileira de Ciência Política, 1(13), 19-51. doi:10.1590/S010333522014000100002

Novaes, R. (2012). A juventude e a luta por direitos. Disponível em: <http://diplomatique.org.br/asjuventudes-e-a-luta-por-direitos/>

Ortiz-Ruiz, N. (2016). ¿Qué mueve a las organizaciones juveniles? Revista Latinoamericana de Ciencias Sociales, Niñez y Juventud, 14(1), 531-543. doi:10.11600/1692715x.14136260215

Santos, L. I. C. (2013). Juventude em foco: a relação juventude-trabalho no Projovem Integrado do município de Natal/RN. (Dissertação de Mestrado). Universidade Federal do Rio Grande do Norte, Natal, Brasil.

Silva, A. B. P. (2014). «Nada é impossível de mudar»: juventude, participação política e o caso da militância juvenil na eleição para prefeito do Rio de Janeiro em 2012. Enfoques, 13(1), 206-224.

Silva, R. S., \& Silva, V. R. (2011). Política Nacional de Juventude: trajetória e desafios. Caderno CRH, 24(63), 663-678. doi:10.1590/S0103-49792011000300013

Sirvent, M. T. (2004). Cultura popular y participación social: una investigación en el barrio de Mataderos. Buenos Aires: Miño y Dávila. 